IZA DP No. 4535

Evaluating the Labor-Market Effects of Compulsory Military Service

Thomas K. Bauer

Stefan Bender

Alfredo R. Paloyo

Christoph M. Schmidt

October 2009 


\title{
Evaluating the Labor-Market Effects of Compulsory Military Service
}

\author{
Thomas K. Bauer \\ RWI Essen, Ruhr University Bochum \\ and IZA \\ Stefan Bender \\ Institute for Employment Research (IAB) \\ Alfredo R. Paloyo \\ RGS Econ, Ruhr University Bochum and RWI Essen
}

\author{
Christoph M. Schmidt \\ RWI Essen, Ruhr University Bochum, \\ CEPR and IZA
}

\section{Discussion Paper No. 4535 \\ October 2009}

\author{
IZA \\ P.O. Box 7240 \\ 53072 Bonn \\ Germany \\ Phone: +49-228-3894-0 \\ Fax: +49-228-3894-180 \\ E-mail: iza@iza.org
}

\begin{abstract}
Any opinions expressed here are those of the author(s) and not those of IZA. Research published in this series may include views on policy, but the institute itself takes no institutional policy positions.

The Institute for the Study of Labor (IZA) in Bonn is a local and virtual international research center and a place of communication between science, politics and business. IZA is an independent nonprofit organization supported by Deutsche Post Foundation. The center is associated with the University of Bonn and offers a stimulating research environment through its international network, workshops and conferences, data service, project support, research visits and doctoral program. IZA engages in (i) original and internationally competitive research in all fields of labor economics, (ii) development of policy concepts, and (iii) dissemination of research results and concepts to the interested public.
\end{abstract}

IZA Discussion Papers often represent preliminary work and are circulated to encourage discussion. Citation of such a paper should account for its provisional character. A revised version may be available directly from the author. 
IZA Discussion Paper No. 4535

October 2009

\section{ABSTRACT}

\section{Evaluating the Labor-Market Effects of Compulsory Military Service ${ }^{*}$}

We identify the causal effect of compulsory military service on conscripts' subsequent labormarket outcomes by exploiting the regression-discontinuity design of the military draft in Germany during the 1950s. Unbiased estimates of the effect of military service on lifetime earnings, wages, and employment are obtained by comparing men born before July 1, 1937 (the "White Cohort") who were exempted from compulsory military service to men who were born on or shortly after this threshold date and hence faced a positive probability of being drafted. We find that the putative earnings advantage and wage premium of those who served in the armed forces vanish when selection effects are taken into account.

JEL Classification: J31

Keywords: causal effect, quasi-experimental estimators, conscription

Corresponding author:

Thomas K. Bauer

RWI Essen

Hohenzollernstr. 1-3

45128 Essen

Germany

E-mail: thomas.bauer@rwi-essen.de

\footnotetext{
* We gratefully acknowledge the comments and suggestions of Daniel Baumgarten, Tobias Klein, Bruno van der Linden, and Justin Smith. All remaining errors are the authors' responsibility. A.R. Paloyo thanks the Leibniz Association for the financial support through RGS Econ.
} 


\section{Introduction}

The recruitment of military personnel varies considerably across countries and over time. While a number of countries, such as the United Kingdom and the United States, has relied and continues to rely on all-volunteer forces, most European countries pursued a policy of compulsory military service (CMS). However, since the end of the Cold War, many European countries recently changed towards all-volunteer forces (e.g., France, Italy, Spain, Portugal, and many Eastern European countries) or are planning to do so in the near future (e.g., Albania, Serbia, Sweden, and Ukraine). Yet many European countries are not planning to abandon the military draft (e.g., Austria, Denmark, Switzerland, Germany, and Greece) despite on-going discussions in most of these countries to do so.

Many economic arguments suggest that a professional army should be preferred because of structural inefficiencies and potential long-run costs that may arise in a draft system. Until recently, much less attention has been put on the long-run effects of CMS for the conscripts, both in the economic literature and the public discussion. ${ }^{1}$ Draftees have to serve in a period of their life that is usually characterized by human capital investments, which is disrupted by the military service. They may further suffer from a deterioration of their human capital stock during service. Even though the long-run effects of CMS may be even more important than the structural inefficiencies, empirical evidence on these long-run effects is rather scarce.

This paper emphasizes the long-run effects of conscription by analyzing the effects of CMS on subsequent labor market outcomes in Germany. However, identifying these effects is problematic for several reasons. Whether someone is drafted for CMS is partially determined by factors which are directly related to labor-market outcomes, such as health status. Access to information on characteristics which determine draft status would enable the researcher to identify the causal effects of military service by

\footnotetext{
${ }^{1}$ See Lau, Poutvaara and Wagener [2004] and Keller, Poutvaara and Wagener [2008] for a recent analysis of the dynamic costs of the draft.
} 
correcting for selection bias. However, these variables are usually not available to the researcher.

In reaction to such deficiencies, previous studies relied on instrumental-variable (IV) estimates [Angrist 1990; Angrist and Krueger 1994; Imbens and van der Klaauw 1995]. These efforts found either a negative effect or no effect of military service on subsequent earnings. For instance, using the year of birth as an instrument for the probability to be drafted for the Vietnam War, Angrist [1990] estimated that ten years after the war, white veterans realized approximately 15 percent lower annual wages than non-veterans. However, the wage differentials between non-white veterans and non-veterans were not statistically significant. Based on IV estimates that utilize the relationship between the date of birth and veteran status, Angrist and Krueger [1994] found that World War II veterans earn the same as non-veterans, if not less. Imbens and van der Klaauw [1995] used variations in the probability to be drafted for CMS across birth cohorts to instrument for military service. They show that ten years after CMS in the Netherlands, those who served earn on average 5 percent less than those who did not serve.

In our analysis, we complement traditional estimation methods with a regressiondiscontinuity (RD) approach to obtain unbiased estimates of the effects of CMS on subsequent labor-market outcomes. ${ }^{2}$ The RD design used here is based on a discontinuity in the probability to be drafted for CMS across birth cohorts in Germany. When creating the new armed forces in the second half of the fifties, all men born before July 1, 1937 were exempted from CMS. On the other hand, men born on July 1, 1937 and after faced a positive probability of being drafted. Based on this rule, we use obser-

\footnotetext{
${ }^{2}$ The RD approach was introduced by Thistlethwaite and Campbell [1960]. It has recently been used, for example, by van der Klaauw [2002] to investigate the effects of financial aid on college enrollment, by Black [1999] to evaluate the effect of elementary-school quality on housing prices, and by Angrist and Lavy [1999] to identify the effect of class size on schooling attainment. Furthermore, Hahn, Todd and van der Klaauw [1999] analyze the effect of an anti-discrimination law on minority employment in small US firms, DiNardo and Lee [2004] estimate the effect of unionization on establishment closure and wages, and Lee [2008] analyzes whether political incumbency provides an advantage in elections to public office. Closest in objective to our paper is the study by Buonanno [2006] who looks at the long-term effects of conscription on earnings and educational attainment in the UK.
} 
vations on the so-called "White Cohort" (Weißer Jahrgang in German, i.e., men who neither served during World War II nor were required to perform CMS) as a control group. ${ }^{3}$

Cross-sectional comparisons of the labor-market outcomes for men who served in the Bundeswehr with those who did not indicate that those men who served apparently enjoy a wage premium. This premium, together with the fact that they remain employed longer than those who did not enter the armed forces, translate to a lifetime earnings advantage of about 17 percent. However, we find that the superior labormarket performance of the draftees is merely the result of the non-random selection mechanism used at that time to admit conscripts. The wage, employment, and earnings differentials vanish when we control for selection bias.

\section{Compulsory Military Service in Germany}

The membership of West Germany in NATO required the creation of the Bundeswehr with a projected maximum strength of around 500,000 soldiers. The West German parliament decided at this time that the Bundeswehr should be composed largely of conscripted men. The corresponding law regulating the introduction of CMS passed the parliament in July 1956. According to this law, all able-bodied men born after June 30, 1937 have to serve in the armed forces. The first 10,000 conscripts entered in May 1957 and they had to serve for 12 months. ${ }^{4}$

\footnotetext{
${ }^{3}$ It is important to note that in the studies of Angrist [1990] and Angrist and Krueger [1994], the samples include people who were actually in a war. Our sample excludes people who were in combat duty. This might explain the negative impact of serving in the Vietnam War on the earnings of veterans. However, updated estimates by Angrist and Chen [2008] using the same instrumental variable show effects that are nearly zero in later periods of the life cycle.

${ }^{4}$ In 1962, the duration of CMS was extended to 18 months and has changed several times since then. In West Germany, women were exempted from CMS. Women were allowed to work voluntarily for the military only in medical professions. In January 2001, the law allowing women to enter combat duty came into force. For conscientious objectors, the German constitution as well as the law on CMS provides the opportunity to perform an alternative type of service. This alternative service mainly comprises auxiliary activities in the health-care sector. In the birth cohorts relevant for the empirical analysis, the fraction of conscientious objectors is small. The first 340 conscientious objectors started their service in April 1961. Until the 1970s, the annual number of conscientious objectors stayed at a negligible level [Haberhauer and Maneval 2000].
} 
In principle, the regulations governing conscription are simple. All men of a particular birth cohort are called for medical and psychological evaluations around their $18^{\text {th }}$ birthday. Based on these examinations, they are divided into three groups: (a) those with good health are categorized as being fit for service; (b) men with smaller health problems are temporarily deferred from service; and (c) men with severe health problems are immediately exempted from military service. Even if the medical and psychological evaluations state that a person is fit to serve, there are various other factors that can lead to an exemption from military service. First, volunteers to the police, the Federal Border Guard, the Peace Corps, and disaster-control workers as well as priests are exempted. Finally, those who have been sentenced to prison because of high treason or the endangering of outer security are not drafted.

The existing economic literature on the individual effects of CMS in Germany concentrates on the implicit income tax placed on the conscripts. This tax equals the difference between the income that those who serve could earn in the civilian market and the usually lower income from military service. Using aggregate data for 1995, Schleicher [1996] calculates that the direct monthly opportunity costs of service for the average German conscript are approximately $€ 1,950$. The total cost of compulsory military and civil service resulting from this implicit tax amounts to more than 27 percent of the official defense budget in 1995. Similar numbers are reported by Schäfer [2000]. ${ }^{5}$ Because of the various exemptions from military service, this implicit income tax is not equally distributed among the male population. Although these opportunity costs and externalities are important, we do not aim to estimate them here. We instead focus on the potential effects of CMS on labor-market outcomes after the service.

The long-term costs of CMS on subsequent labor-market outcomes could be expected to be numerically at least as important as the direct opportunity costs of service, if not more. Usually, potential recruits are not immediately drafted after either

\footnotetext{
${ }^{5}$ In the US, the direct costs of military service received increasing attention already in the 1960s. See, among others, Bailey and Cargill [1969], Davis and Palomba [1968], Fisher [1969], Hansen and Weisbrod [1967], Oi [1967], and Spencer and Woroniak [1969].
} 
their health examinations or the end of their temporary exemptions. They will rarely be able to foresee when exactly they will be called to serve. Due to this uncertainty, it may be difficult for them to find permanent employment. They may be obliged to accept casual employment and are more likely to be unemployed [Oi 1967]. This tenuous labor-market status during the waiting period may have detrimental effects on the human capital of potential recruits in terms of lower job training or occupationspecific skills. Hence, it may result in relatively lower earnings and worse employment prospects even after military service. It has further been argued that conscripts suffer from a deterioration of their human-capital stock during their time of service [Spencer and Woroniak 1969]. Since the wages paid by the armed forces to the conscripts are in most cases lower than their market wage, armed forces that rely on conscription usually suffer from an inefficiently low capital-labor ratio. This further suggests that the armed forces have no incentive to use the human capital of conscripts in an efficient way and to allocate them to appropriate jobs within the military sector.

However, military service may also have positive effects on the human-capital stock of the conscripts and hence enhance their labor-market performance. During military service, conscripts may acquire soft skills such as working in a team and in a strict hierarchical structure. These skills may be rewarded in the civilian labor market. Furthermore, performing CMS may be used by potential employers as a signal for good health status or a high sense of responsibility, resulting in positive statistical discrimination in favor of those who served. This preferential treatment that former conscripts could potentially receive in the labor market could translate into a wage premium.

Overall, the long-term labor-market effects of CMS are not easily predictable. As discussed above, there are convincing arguments on both sides such that the ultimate effect is uncertain. However, any such effect-positve or negative-assumes that the resulting differential performance in the labor market is caused by military service. We contribute to the analysis by estimating the net effect with what we believe is a 
solid econometric identification strategy that controls for the likely selection bias that arises in conscription.

\section{Regression-Discontinuity Design}

Investigating the effects of CMS on subsequent labor-market outcomes presents a classical evaluation problem. Since men are either drafted or not drafted, we do not observe a single individual in both states. Consider any generic labor-market outcome of interest, say, lifetime earnings. Suppose that this outcome is determined by the equation:

$$
Y_{i}=\alpha_{i}+\tau M_{i}+\epsilon_{i}
$$

where $Y_{i}$ denotes the lifetime earnings of individual $i, M_{i}$ is the treatment indicator that equals 1 if individual $i$ performed CMS and 0 otherwise, and $\epsilon_{i}$ is a stochastic disturbance term. Our parameter of interest is $\tau \equiv \mathrm{E}\left[Y_{i} \mid M_{i}=1\right]-\mathrm{E}\left[Y_{i} \mid M_{i}=0\right]$, which is the earnings premium or penalty of serving in the Bundeswehr. If treatment is non-random, simple OLS estimates of $\tau$ will be biased since $\mathrm{E}\left[\epsilon \mid M_{i}\right] \neq 0$. Such a selection bias in the estimate of $\tau$ could occur, for example, because the health status of an individual affects both the probability to be drafted for CMS and lifetime earnings $Y_{i}$. In the RD approach, additional information about discontinuities in the probability to be selected into treatment $\mathrm{P}\left[M_{i}=1 \mid X_{i}\right]$ is used to obtain consistent estimates of $\tau{ }^{6}$

Apart from the treatment indicator $M_{i}$, let $W_{i}$ be in indicator variable that equals 1 if a man was born at or after July 1, 1937 and 0 otherwise. One could thus distinguish three groups: men born before July 1, 1937 (the White Cohort) who were altogether exempted from military service $\left(M_{i}=0\right.$ and $\left.W_{i}=0\right)$; men born at or after July 1 , 1937 who could in principle be drafted for military service but who were exempted due to one of the reasons described in the last section $\left(M_{i}=0, W_{i}=1\right)$; and men

\footnotetext{
${ }^{6}$ We give a cursory treatment of RD designs here. For a more thorough discussion, including the asymptotic behavior of these estimators, the interested reader is referred to the authoritative article of Hahn, Todd and van der Klaauw [2001].
} 
born at or after July 1, 1937 who were drafted for CMS $\left(M_{i}=1, W_{i}=1\right)$. Hence, for the full sample of individuals, the conditional probability of receiving treatment $M_{i}$ is known to be discontinuous at a threshold value $\bar{B}$, i.e., the date of birth that separates the White Cohort from the rest.

The literature on the RD approach typically differentiates between two types of discontinuities [Trochim 1984]. The case where treatment $M_{i}$ is known to depend on $B_{i}$ in a deterministic way is called the sharp design. If $M_{i}$ depends on $B_{i}$ in a stochastic way, it is called the fuzzy design. Note that our case could be considered a mixture of the sharp and fuzzy designs. ${ }^{7}$ Let $\bar{B}$ denote the threshold birthday of July $1,1937$. We know that men born before $\bar{B}$ are exempted from military service, i.e., $\mathrm{E}\left[M_{i} \mid B_{i}<\right.$ $\bar{B}]=0$, whereas the probability to be drafted for military service is a function of some individual characteristics $X_{i}$, such as health status, for those born at or after $\bar{B}$, i.e., $\mathrm{E}\left[M_{i} \mid B_{i} \geq \bar{B}\right]=f\left(X_{i}\right)+\eta_{i}$

The RD approach makes use of the expectation that individuals who are just below the threshold value $\bar{B}$ are similar in their observed and unobserved characteristics to individuals who are just above $\bar{B}$ but for the probability of being selected into treatment. Hence, the distribution of observed and unobserved characteristics of individuals born just before July 1, 1937 will be arbitrarily close to the distribution of observed and unobserved characteristics of individuals born at or just after this date, i.e., for individuals born near the cutoff point, it could be expected that $\mathrm{E}\left[\alpha_{i} \mid B_{i}=\bar{B}+\Delta\right]=\mathrm{E}\left[\alpha_{i} \mid B_{i}=\bar{B}-\Delta\right]$, where $\Delta$ denotes an arbitrarily small number.

Assuming that the unknown parameter $\eta$ in $\mathrm{E}\left[M_{i} \mid B_{i}\right]=f\left(X_{i}\right)+\eta_{i}$ is an independent assignment error, i.e., $\operatorname{Cov}(\epsilon, \eta)=0$, the treatment parameter $\tau$ can be consistently estimated by implementing the regression:

$$
Y_{i}=\alpha+\tau M_{i}+g\left(B_{i}\right)+v_{i}
$$

\footnotetext{
${ }^{7}$ Battistin and Rettore [2008] call this the "partially fuzzy design".
} 
where $g\left(B_{i}\right)$ is a control function that is continuous in $B$ and represents a specification of $\mathrm{E}\left[\epsilon \mid B_{i}\right]$. However, if $\eta$ is not independent of $\epsilon$ given $M$, the estimate of $\tau$ in Equation (1) is biased. The resulting selection bias depends on $\operatorname{Cov}(X, \epsilon \mid M)$ and may take any sign [van der Klaauw 2002].

The literature on the RD approach suggests two solutions to this selection-bias problem. Van der Klaauw [2002] proposes a two-step estimation procedure. Let $W_{i}=1$ if $B_{i}>\bar{B}$ and $W_{i}=0$ otherwise. In the first step, the propensity score is estimated using

$$
\mathrm{E}\left[M_{i} \mid B_{i}\right]=f\left(B_{i}\right)+\delta W_{i}
$$

where $f\left(B_{i}\right)$ is some function of $B$ that is continuous in $B$. In the second stage, $M_{i}$ in Equation (2) is replaced by the first-stage estimates of $\mathrm{E}\left[M_{i} \mid B_{i}\right]$ :

$$
Y_{i}=\alpha+\tau \mathrm{E}\left[M_{i} \mid B_{i}\right]+g\left(B_{i}\right)+v_{i}
$$

If the functions for $g\left(B_{i}\right)$ and $f\left(B_{i}\right)$ are specified correctly, Equation (4) produces consistent estimates of the treatment effect $\tau$. If $g\left(B_{i}\right)$ and $f\left(B_{i}\right)$ are modelled parametrically using the same functional form, this two-stage procedure reduces to a standard 2SLS IV estimator, where $W_{i}$ and $f\left(B_{i}\right)$ are used as instruments (and are hence assumed to be orthogonal to $v_{i}$ ) [Wald 1940].

In our empirical analysis, we constrain $f\left(B_{i}\right)$ to be equal to $g\left(B_{i}\right)$ and then proceed to estimate the system of Equations (3) and (4) twice: (a) using a higher-order polynomial and (b) a restricted cubic spline of the difference in days of an individual's date of birth $B_{i}$ and the threshold date $\bar{B}$. We further use three quarter-of-birth dummies and two dummies representing the educational attainment of an individual. An advantage of this two-step approach is that the identification of $\tau$ uses all observations over $B$. One limitation is that it is more fragile towards misspecification because consistent estimates of $\tau$ crucially depend on the correct specification of $f\left(B_{i}\right)$ and $g\left(B_{i}\right)$.

To overcome this deficiency, Hahn, Todd and van der Klaauw [2001] propose a 
non-parametric approach. Assume that both $\mathrm{E}\left[\alpha_{i} \mid B_{i}=B\right]$ and the conditional mean function $\mathrm{E}\left[\epsilon_{i} \mid B\right]$ are continuous at $\bar{B}$. Assuming further that the treatment effect is constant across different individuals, the average treatment effect is identified as the following ratio:

$$
\tau=\frac{\lim _{B \downarrow \bar{B}} \mathrm{E}\left[Y_{i} \mid B_{i}=B\right]-\lim _{B \uparrow \bar{B}} \mathrm{E}\left[Y_{i} \mid B_{i}=B\right]}{\lim _{B \downarrow \bar{B}} \mathrm{E}\left[M_{i} \mid B_{i}=B\right]-\lim _{B \uparrow \bar{B}} \mathrm{E}\left[M_{i} \mid B_{i}=B\right]}=\frac{Y^{+}-Y^{-}}{M^{+}-M^{-}} .
$$

The limits $Y^{+}, Y^{-}, M^{+}$, and $M^{-}$can be estimated using one-sided kernel regressions. The advantage of this approach compared to the two-step estimation procedure suggested by van der Klaauw [2002] is that it does not require the specification of $f\left(B_{i}\right)$ and $g\left(B_{i}\right)$ or indeed the inclusion of any other covariate. ${ }^{8}$ However, a disadvantage is that the treatment effect is estimated using only observations near the threshold $\bar{B}$ and that non-parametric estimation of the limits requires the choice of a kernel function and of an appropriate bandwidth. Because of the poor boundary performance of standard kernel estimators, Hahn, Todd and van der Klaauw [2001] propose the use of local linear regressions suggested by Fan [1992] to estimate the limits.

The denominator in Equation (5) is nonzero because $\mathrm{P}\left[M_{i}=1 \mid B_{i}=B\right]$ is discontinuous at $\bar{B}$. Our case represents a mixture between the sharp and the fuzzy RD designs because $M^{-}$always equals 0 . Hence, the average treatment effect is identified by

$$
\tau=\frac{Y^{+}-Y^{-}}{M^{+}}
$$

Viewed from this practical perspective, the sharp RD design is essentially a special case of its fuzzy counterpart where the estimate of the jump around the cutoff for the outcome variable is not rescaled by the jump in the probability of treatment. [Lee and Lemieux 2009] More accurately, however, the partially fuzzy design requires only the same regularity conditions needed for identification in a sharp RD design. [Battistin

\footnotetext{
${ }^{8}$ Covariates can be included with the aim of reducing sampling variability. Nevertheless, as long as the assumptions underlying identification is fulfilled, the RD estimator will be unbiased. [Lee and Lemieux 2009]
} 
and Rettore 2008]

One could think of the fuzzy RD estimator as a "local" estimator in two ways. First, a limitation of the RD approach is that the treatment effect can only be identified for persons with values of $B_{i}$ that are near $\bar{B}$. Second, in this neighborhood, the treatment effect is identified only for the "compliers" or that sub-group of individuals for whom the probability of treatment changes discontinuously at $\bar{B}$ [Imbens and Lemieux 2008]. Allowing for heterogeneous treatment effects requires the additional assumption that treatment $M_{i}$ is independent of $\tau$ conditional on being near the threshold $\bar{B}$ (local conditional independence assumption), i.e., that the potential costs of or returns to treatment do not change the behavior of individuals in such a way that they try to influence the treatment probability. ${ }^{9}$ Under this assumption, the ratio defined in Equation (5) identifies a local average treatment effect (LATE) in the sense proposed by Imbens and Angrist [1994]. As such, the external validity of RD estimates is not apparent ${ }^{10}$ but its internal validity is widely believed to be unparalleled by other quasi-experimental methods relied upon to draw causal inferences [Imbens and Wooldridge 2009; Lee and Lemieux 2009].

\section{Data Construction and Description}

We use process-generated German register data provided by the Institute for Employment Research (IAB) and generated by an integrated notifying procedure for the public health insurance, statutory pension scheme, and unemployment insurance, which was introduced in 1973. By law, employers have to provide information to the social security agencies for employees acquiring claims to the social security system. These

\footnotetext{
${ }^{9}$ When economic agents can precisely manipulate their behavior at the cutoff point, the RD design fails to identify any meaningful treatment effect [Lee 2008; Urquiola and Verhoogen 2009]. However, as long as the manipulation is imprecise, the situation in a small neighborhood around the discontinuity can still be considered a local random experiment for which the RD approach is well-suited [Lee and Lemieux 2009].

${ }^{10}$ Although that is debatable. See, e.g., the discussion in Lee and Lemieux [2009] and their interpretation of the gap at the cutoff point as a "weighted average treatment effect" that is generalizable.
} 
notifications are required at the start and end of any employment relationship. In addition, employers are obliged to provide an annual report for each employee who is employed on the $31^{\text {st }}$ of December of each year and covered by social insurance. The reports include information on sex, year of birth, nationality, occupation, qualification, as well as the gross wage rate of the employee. According to the obligation to register with the state pension authorities, the data encompass all persons who have paid contributions to the pension system or who have been covered by the pension system through contributions by the unemployment insurance. As a consequence, certain groups of employees (e.g., temporary civil servants or self-employed persons) are not covered by the data.

We combine the IAB employment sample with additional administrative data assembled at the state pension authorities (IAB employment supplement sample; IAB-S). Both datasets can be linked by the social security number. The matched file contains a 1-percent random sample of the total German population that was gainfully employed for at least one day between 1975 and 1995 (for details, see Bender, Haas and Klose [2000]). ${ }^{11}$ Note that the IAB-S is an event-data set, which enables us to obtain labor-market information on a daily basis.

The IAB-S offers several advantages. First, as opposed to other datasets in Germany, the IAB-S allows identification of persons who served in the Bundeswehr. In particular, we can distinguish between regular employment, unemployment, and other "non-active" states such as maternity leave, illness, disability, full-time education, and military service. The dataset also has exact information on the date of birth which allows us to separate persons in the White Cohort from persons who faced a positive probability of being drafted for military service. Finally, it is large enough to have sufficient observations around the threshold date of July 1, 1937 to meaningfully apply the RD approach.

\footnotetext{
${ }^{11} \mathrm{~A}$ new version of the IAB-S will be available for researchers via the Research Data Center of the German Employment Agency in the Institute for Employment Research (RDC-IAB) in 2011. See http: //fdz.iab.de/en/FDZ_Projects/BASID.aspx/.
} 
From the original sample, we deleted all females, East Germans, and all persons that lived outside of West Germany at one point in time, including foreigners and ethnic German immigrants. We further restricted our analysis to persons born between January 1, 1934 and December 31, 1940 who worked for at least one day in our sample period. The latter selection was mainly driven by the desire to capture a symmetric range of birth cohorts around the threshold year of 1937 and to limit the probability that a non-negligible fraction of individuals in our sample serves in alternative functions other than military service. Furthermore, individuals in the sample should not serve more than 12 months. Thus, we are able to concentrate our empirical analysis on those men who were in the Bundeswehr with the same duration of service. Professional soldiers and those who started CMS and then decided to become professional soldiers have also been dropped from our sample.

Figure 1 shows the average number of conscripts by date of birth. The figure shows that about 18 percent of the men born in July 1937 have been drafted for military service. The share of conscripts is slightly decreasing for men born between July 1937 and August 1938 and is sharply increasing for men born after the middle of 1938 . This development could be explained by temporary frictions in building up the Bundeswehr in the initial years and the gradual intensification of the Cold War. In addition, several special exemptions applied in the first years of the Bundeswehr. For example, sole sons of a soldier killed in World War II or a soldier still missing were exempted. This rule applied to about 10 percent of the men in the birth cohorts from 1937 to 1944 [Wehrstruktur-Kommission 1971]. Those who lost all brothers or all sisters could also request for an exemption. Additionally, persons who are examined to be fit for service could defer the draft if they face a personal, economic, or occupational situation in which the draft would be a serious hardship. This deferment could result in a permanent exemption when these persons reached the maximum age limit of 25 for the initiation of military service. According to the Wehrstruktur-Kommission [1971], about 3.5 percent of all men in a birth cohort received a permanent exemption from 
military service in the 1960s because they were older than 25 .

As a composite indicator of labor-market success, we consider the cumulative real earnings from 1963 to 1988 . We also investigate the effect of CMS on the cumulative days of employment within the same period. Differences in real wages at different points in the life cycle and cumulative earnings might be the result of differences in accumulated labor-market experience due to distinct probabilities of becoming unemployed, sick, or leaving the labor market. Therefore, we also analyze the effects of CMS on lifetime average daily wage, defined as the cumulative earnings divided by the cumulative days of employment. Finally, we consider the real daily gross wage for each year in the sample.

Table 1 and Figures 2 and 3 report some descriptive statistics of the variables used in our analysis. In Table 1, the cumulative lifetime earnings and lifetime average daily wage of individuals from the White Cohort are less than those born at or after July 1 , 1937. For the lifetime average daily wage and educational attainment, the differences are statistically significant. However, this difference disappears when we restrict the sample to those born in $1937 .{ }^{12}$ The reported real daily wages at age 30, 40, and 50 show the typical concave pattern over the life cycle that could be observed in almost all developed countries.

Throughout the life cycle, individuals that served in the military earn more than both individuals from the White Cohort and individuals born after July 1, 1937 who were not drafted for military service. Figures 2(a) and 2(b) show the age-earnings profiles by group for the full sample and the sample of individuals born in 1937, respectively. Those who served in the Bundeswehr earn more than both those who did not serve and those from the White Cohort. Note that the respective earnings differentials are smaller if we restrict our sample to individuals born in 1937. A similar picture emerges if we look at lifetime average wages, cumulative days of employment, and cumulative lifetime earnings, which are depicted in Figures 3(a), 3(b), and 3(c), respec-

\footnotetext{
${ }^{12}$ These tests are available upon request.
} 
tively. The differences between those who served in the military and the rest of the sample are even starker in these graphs. Draftees seem to enjoy a remarkable advantage over non-draftees. However, these simple comparisons do not inform us about the causal impact of CMS on labor-market outcomes because of the selection mechanism which we have yet to take into account.

\section{Estimation Results}

\subsection{OLS Results}

The estimated returns to military service obtained by OLS regressions are shown in Figure 4 and Table 2. The estimated coefficients in Figure 4 are obtained from OLS regressions of (log) real daily gross wage on a dummy variable indicating whether an individual served in the Bundeswehr, two education dummies ${ }^{13}$, age, and quarterof-birth dummies. These regressions are performed separately for each year in the sample. The figure shows that for both sub-samples depicted, the returns to military service are slightly increasing over time. Using the full sample (Figure 4(a)), the estimated returns to military service starts out at almost 1 percent in 1963 and ends at about 3 percent in 1988. Using only individuals born between 1936 and 1938 provides a somewhat similar picture (Figure 4(b)) although the standard errors of the estimates are naturally higher because of the reduced sample size.

Table 2 shows the estimated returns to military service when using lifetime average daily wage, cumulative days of employment, and cumulative lifetime earnings as dependent variables, with the aforementioned controls present in the regressions. Using the full sample, the results suggest that over their entire life cycle, those who served in the Bundeswehr have wages that are about 4.6 percent higher than the wages of those

\footnotetext{
${ }^{13}$ We use the term "high school" to refer to indivduals who have successfully completed either an apprenticeship or the Abitur, the qualification exam to enter university. "University" is reserved for those who earned a degree from a Hochschule (tertiary education), which is not the same as secondary education referred to by its literal English translation into "high school". The reference category is non-completion of an apprenticeship, an Abitur, or a university degree.
} 
who have been exempted or are born before July 1, 1937 (Panel A, Column (2) of Table 2). In terms of the effect of CMS on the number of days of employment (Panel B), we find that those who served in the Bundeswehr work 13 percent more days than their counterparts who did not enter the armed forces. Taken together, these effects amount to a cumulative lifetime earnings (Panel C) advantage of about 17 percent. The results are very similar when restricting the sample to those born in the period 1936-1938.

\subsection{RD Results}

The estimated returns to military service using OLS are biased due to the non-random selection of the conscripts described in Section 2. We account for this by presenting RD estimates in Table 3 and Figure 5. In Table 3, the results for Panel A are based on 2SLS regressions while the estimates for Panel B come from local linear regressions. For the 2SLS procedure, we use a quartic polynomial of the difference between an individual's date of birth and $\bar{B}$ measured in days and its interaction with a dummy variable which equals 1 for non-White Cohort observations. ${ }^{14}$ This appears in both the first-stage and the second-stage regressions (i.e., $f\left(B_{i}\right)$ is equal to $g\left(B_{i}\right)$; see Equations (3) and (4)), with the indicator variable serving as the lone excluded instrument. Alternatively, both $f\left(B_{i}\right)$ and $g\left(B_{i}\right)$ are modelled as cubic splines (piecewise cubic polynomials) to more flexibly account for non-linearities. Quarter-of-birth and level-of-education controls further serve as included instruments. The point estimates indicate that those who served in the Bundeswehr have a cumulative lifetime earnings disadvantage of about 2 to 8 percent. However, this is mostly driven by the reduction in the days of employment (as high as 16 percent based on the polynomial regressions) since the lifetime average daily wage actually increases (Columns (1) and (2)). However, these returns are imprecisely estimated.

\footnotetext{
${ }^{14}$ We proceed to estimate the system using 2SLS despite the binary nature of the endogenous variable since consistent estimation of the parameter of interest in the second stage is unaffected by a linear approximation of the conditional expectation function in the first stage [Heckman 1978; Angrist and Krueger 1994]. However, the standard errors are clustered at the day of birth to allow for an arbitrary correlation structure within each cohort [Lee and Card 2008].
} 
Local linear estimates are presented in Figure 5 and Panel B of Table 3. The limits $Y^{+}, Y^{-}$, and $M^{+}$described in Equation (6) are estimated using local linear regressions around the point of discontinuity. In Figure 5, we graphically represent the difference between $Y^{+}$and $Y^{-}$. From the confidence-interval bands, one can see that there is no statistical difference between the estimates on both sides of the threshold. ${ }^{15}$ However, the point estimates at the cutoff give an indication of the direction of the causal impact of CMS on labor-market outcomes which are consistent with the 2SLS estimates.

In Panel B of Table 3, we report estimates based on two different kernels (triangular and rectangular) and three different bandwidth choices. The preferred bandwidth is derived through a "rule of thumb" (see StataCorp [2007] for details); we then reestimate the model with the preferred bandwidth reduced by 50 percent and then again increased by 50 percent. The direction of the estimates from the parametric regressions in Panel A carry over to the non-parametric setup in Panel B. The imprecision over the estimates is also sustained. One reason for the inflated standard errors is the drastic reduction in the sample size over which the estimates are computed. This can be seen more clearly when one compares the standard errors obtained from different bandwidths. The smallest window (50 percent of the preferred bandwidth) has the highest standard errors across the board. As the imprecision over the estimates is driven by the methodology itself, we would like to think of this set of non-parametric estimates as primarily a robustness check on the polynomial- and spline-based estimates presented in Panel A. Thus, in terms of the direction of the causal effect of CMS on labor-market outcomes, the parametric estimates using the whole sample are confirmed by the local linear regression results.

\footnotetext{
${ }^{15}$ The graphs are constructed using the triangular kernel. The graphs based on the rectangular kernel look similar and are available from the authors.
} 


\subsection{Validity of the RD Design}

The validity of the RD approach largely rests on the assumption that individuals near the threshold value $\bar{B}$ are similar with regard to their observed and unobserved characteristics. If this assumption were true, an implication is that the distribution of covariates that are presumably not affected by the forcing variable $B_{i}$ should be continuous at $\bar{B}$. This is similar in spirit to placebo regressions that are now commonly done in the evaluation literature. Unfortunately, the IAB-S provides only limited information on those characteristics of the individuals which are determined before a potential draft (i.e., the traits unaffected by military service). The only variable which largely satisfies these requirements is educational attainment. For most men, pre-university schooling is already completed at the time of their draft. However, for those planning to graduate from university, the draft usually occurs between the completion of high school and the start of university education. For these men, the draft defers university education but does not necessarily affect the decision to obtain a university degree. ${ }^{16}$ In our case, we see this most obviously in Figure 6(a), where the share of men who completed the qualification exam to enter university is rendered over the running variable.

Another piece of evidence to support the RD approach is the continuous distribution (over the threshold) of other covariates that could affect the outcome variables used in the analysis. If these variables are continuous at the critical point, then the change in the outcome variable could entirely be attributed to the treatment. In Figure 6(b), we observe that there is a slight discontinuity in the share of men who completed a university degree but the difference is small and also well-within the 95percent confidence intervals. Taken together, the behavior of the other covariates over the forcing variable lead credence to the $\mathrm{RD}$ approach taken here.

\footnotetext{
${ }^{16}$ Those persons who are categorized to be fit for service and start their university education before being drafted could apply for a temporary exemption from military service until they receive their university degree. According to the law, however, they have to expect to be drafted before the maximum age limit of 25, irrespective of whether they finished their degree. Hence, there are strong incentives to enter military service before starting university education. The law further limits the possibilities to decide to go to university just to avoid the draft to military service.
} 
Finally, we test for possible discontinuities in the sample where there should be no discontinuity. To implement this test, we split the sample into non-White Cohort and White Cohort observations. For each of the sub-samples, we take the median of the forcing variable and simulate a discontinuity at this value of $B$. Then, we estimate the impact of this simulated discontinuity on the outcome variables. We expect that there should be no significant effect on labor-market outcomes (i.e., that there should be no discontinuity in $Y$ ) since, in reality, there was no treatment at this point. Indeed, these placebo regressions indicate that there are no unexpected discontinuities that could put into question the RD design. ${ }^{17}$

\subsection{Alternative IV Results}

As noted above, the RD design identifies a LATE that may not be generalizable to birth cohorts other than those around the threshold date. We therefore present alternative IV results with which to compare the RD estimates. Here, we follow Imbens and van der Klaauw [1995] by using variations in the average conscription rate by month of birth as an instrument for serving in the Bundeswehr. The probability to be drafted depends, among other things, on the size of the birth cohort. With a relatively constant demand for conscripts, the Bundeswehr tacitly tightens its requirements for enlistment in the case of a large birth cohort while it loosens these same requirements when a birth cohort yields less potential draftees. The control variables are the same as the ones used for the OLS estimates discussed in Section 5.1. While the RD estimates are local in two dimensions (they identify the treatment effect for the compliers around the neighborhood of the discontinuity), the IV estimates presented here are local only in the sense that they identify the treatment effect for the compliers. We find that the estimates are not substantially different from the ones obtained using the RD approach.

The results from these IV estimations are reported in Table 4 and Figure 7. In Ta-

\footnotetext{
${ }^{17}$ These tests are available upon request.
} 
ble 4 , the returns to military service in terms of the lifetime average daily wage are positive and higher than the corresponding OLS estimates in Table 2. However, because of the reduction in the cumulative days of employment, the resulting estimates for the effect on cumulative lifetime earnings are less than the OLS estimates. In Figures 7(a) and 7(b), the IV estimates of the impact of CMS on the (log) real daily gross wage show roughly the same evolution as Figures 4(a) and 4(b). Nevertheless, these point estimates do not statistically differ from 0 . Ultimately, accounting for the selection effects during the draft through the use of an instrumental variable produces insignificant estimates of the returns to CMS.

\section{Conclusion}

The costs and benefits of serving in the military for the conscripts themselves have not been thoroughly examined in Germany. This issue is particularly relevant as policymakers are considering a shift from a system of conscription to that of voluntary enlistment. A proponent of maintaining conscription may point to the fact that, in terms of wages, employment, and lifetime earnings, men who served in the Bundeswehr end up performing better than those who did not serve. That is, the costs-if any-of performing military service are outweighed by its benefits. Such benefits may be due to the transfer of valued skills learned in the armed forces to the civilian labor market or outright preferential treatment for draftees. However, such a comparison would fail to take into account the manner in which these men were selected into the Bundeswehr.

When we correct for the selection bias, we find that CMS has no long-run impact on the labor-market performance of conscripts. Therefore, the observed earnings differential between conscripts and non-conscripts could entirely be attributed to the way the former were selected into the armed forces. Consider the likely case wherein these men are healthier than their rejected or exempted counterparts. To the extent that a better health status contributes to a better labor-market outcome, it would be rea- 
sonable to say that conscripts would have earned more even without serving in the Bundeswehr. We conclude that the observed differences between those who served and those who did not serve cannot be attributed to military service. 


\section{References}

Angrist, Joshua D. 1990. "Lifetime Earnings and the Vietnam Era Draft Lottery: Evidence from Social Security Administrative Records." American Economic Review 80(3):313-336.

Angrist, Joshua D. and Alan B. Krueger. 1994. "Why Do World War II Veterans Earn More than Nonveterans?" Journal of Labor Economics 12(1):74-97.

Angrist, Joshua D. and Stacey H. Chen. 2008. "Long-Term Economic Consequences of Vietnam-Era Conscription: Schooling, Experience and Eearnings." Forschungsinstitut zur Zukunft der Arbeit (IZA) Bonn: IZA Discussion Paper No. 3628.

Angrist, Joshua D. and Victor Lavy. 1999. "Using Maimonides' Rule to Estimate the Effect of Class Size on Scholastic Achievement." Quarterly Journal of Economics 114(2):533-575.

Bailey, Duncan and Thomas F. Cargill. 1969. "The Military Draft and Future Income." Western Economic Journal 7(4):365-370.

Battistin, Erich and Enrico Rettore. 2008. "Ineligibles and Eligible Non-Participants as a Double Comparison Group in Regression-Discontinuity Designs." Journal of Econometrics 142(2):715-730.

Bender, Stefan, Anette Haas and Christoph Klose. 2000. “The IAB Employment Subsample 1975-1995: Opportunities for Analysis Provided by the Anonymised Subsample." Forschungsinstitut zur Zukunft der Arbeit (IZA) Bonn: IZA Discussion Paper No. 117.

Black, Sandra E. 1999. “Do Better Schools Matter? Parental Valuation of Elementary Education." Quarterly Journal of Economics 114(2):577-599.

Buonanno, Paolo. 2006. "Costs of Conscription: Lessons from the UK." University of Bergamo: Department of Economics Working Paper No. 04/2006.

Davis, J. Ronnie and Neil A. Palomba. 1968. "On the Shifting of the Military Draft as a Progressive Tax-in-Kind." Western Economic Journal 6(2):150-173.

DiNardo, John and David S. Lee. 2004. "Economic Impacts of New Unionization on Private Sector Employers: 1984-2001." Quarterly Journal of Economics 119(4):13831441.

Fan, Jianqing. 1992. "Design-Adaptive Nonparametric Regression." Journal of the American Statistical Association 87(420):998-1004.

Fisher, Anthony C. 1969. "The Cost of the Draft and the Cost of Ending the Draft." American Economic Review 59(3):239-254.

Haberhauer, Margarete and Helmut Maneval. 2000. “Kriegsdienstverweigerung in der Bundesrepublik Deutschland." Jahrbücher für Nationalökonomie und Statistik 220(2):129-146. 
Hahn, Jinyong, Petra Todd and Wilbert van der Klaauw. 1999. "Evaluating the Effect of an Antidiscrimination Law Using a Regression-Discontinuity Design." National Bureau of Economic Research (NBER) Cambridge: NBER Working Paper Series No. 7131.

Hahn, Jinyong, Petra Todd and Wilbert van der Klaauw. 2001. "Identification and Estimation of Treatment Effects with a Regression-Discontinuity Design." Econometrica 69(1):201-209.

Hansen, W. Lee and Burton A. Weisbrod. 1967. "Economics of the Military Draft." Quarterly Journal of Economics 81(3):395-421.

Heckman, James J. 1978. “Dummy Endogenous Variables in a Simultaneous Equation System." Econometrica 46(4):931-959.

Imbens, Guido W. and Jeffrey M. Wooldridge. 2009. "Recent Development in the Econometrics of Program Evaluation." Journal of Economic Literature 47(1):5-86.

Imbens, Guido W. and Joshua D. Angrist. 1994. "Identification and Estimation of Local Average Treatment Effects." Econometrica 62(2):467-475.

Imbens, Guido W. and Thomas Lemieux. 2008. "Regression Discontinuity Designs: A Guide to Practice." Journal of Econometrics 142(2):615-635.

Imbens, Guido W. and Wilbert van der Klaauw. 1995. "Evaluating the Cost of Conscription in the Netherlands." Journal of Business E Economic Statistics 13(2):207-215.

Keller, Katarina, Panu Poutvaara and Andreas Wagener. 2008. "Military Draft and Economic Growth in OECD Countries." University of Helsinki: Helsinki Center of Economic Research Discussion Paper No. 228.

Lau, Morten I., Panu Poutvaara and Andreas Wagener. 2004. "Dynamic Costs of the Draft." German Economic Review 5:381-406.

Lee, David S. 2008. "Randomized Experiments from Non-Random Selection in U.S. House Elections." Journal of Econometrics 142(2):675-697.

Lee, David S. and David Card. 2008. "Regression Discontinuity Inference with Specification Error." Journal of Econometrics 142(2):655-674.

Lee, David S. and Thomas Lemieux. 2009. "Regression Discontinuity Designs in Economics." National Bureau of Economic Research (NBER) Cambrdige: NBER Working Paper Series No. 14723.

Oi, Walter Y. 1967. "The Economic Cost of the Draft." American Economic Review 57(2):39-62.

Schäfer, Wolf. 2000. “Wehrpflicht oder Freiwilligenarmee? Die Wehrstruktur aus ökonomischer Sicht." Wirtschaftdienst 80(6):343-349. 
Schleicher, Michael. 1996. Die Ökonomie der Wehrpflicht: Eine Analyse unter besonderer Berücksichtigung der Grundsätze der Besteuerung. Frankfurt am Main et al.: Lang.

Spencer, Daniel L. and Alexander Woroniak. 1969. "Valuing Transfer of MilitaryAcquired Skills to Civilian Employment." Kyklos 22(3):467-492.

StataCorp. 2007. Stata Statistical Software: Release 10. College Station, TX: StataCorp LP.

Thistlethwaite, Donald L. and Donald T. Campbell. 1960. "Regression-Discontinuity Analysis: An Alternative to the Ex Post Facto Experiment." Journal of Educational Psychology 51(6):309-317.

Trochim, William M. K. 1984. Research Design for Program Evaluation: The RegressionDiscontinuity Approach. Beverly Hills, CA: Sage Publications.

Urquiola, Miguel and Eric Verhoogen. 2009. "Class-Size Caps, Sorting, and the Regression-Discontinuity Design." American Economic Review 99(1):179-215.

van der Klaauw, Wilbert. 2002. "Estimating the Effect of Financial Aid Offers on College Enrollment: A Regression-Discontinuity Approach." International Economic Review 43(4):1249-1287.

Wald, Abraham. 1940. "The Fitting of Straight Lines if Both Variables Are Subject to Error." Annals of Mathematical Statistics 11(3):284-300.

Wehrstruktur-Kommission. 1971. Wehrgerechtigkeit in der Bundesrepublik Deutschland. Bericht der Wehrstruktur-Kommission an die Bundesregierung 1971. Bonn: Wehrstruktur-Kommission. 


\section{Appendix}

\section{A.1 Tables}

TABle $1-$ VARiable MeAns AND STANDARD DEVIATIONS

\begin{tabular}{|c|c|c|c|c|}
\hline & \multirow{2}{*}{ White Cohort } & \multicolumn{3}{|c|}{ Not White Cohort } \\
\hline & & Total & Drafted & $\begin{array}{c}\text { Not } \\
\text { Drafted }\end{array}$ \\
\hline \multirow[t]{2}{*}{ Age in 1988} & 53.1880 & 49.6762 & 49.3060 & 49.7553 \\
\hline & [1.0157] & [0.9927] & [0.9681] & [0.9799] \\
\hline \multirow[t]{2}{*}{ No Educational Degree* } & 0.2799 & 0.2446 & 0.1701 & 0.2605 \\
\hline & [0.4490] & [0.4298] & [0.3758] & [0.4389] \\
\hline \multirow{2}{*}{ Completed Apprenticeship* } & 0.6584 & 0.6791 & 0.7939 & 0.6545 \\
\hline & [0.4743] & [0.4669] & [0.4046] & [0.4756] \\
\hline \multirow{2}{*}{ Passed Abitur* } & 0.0616 & 0.0764 & 0.0360 & 0.0850 \\
\hline & {$[0.2405]$} & [0.2656] & [0.1863] & [0.2789] \\
\hline \multirow[t]{2}{*}{ University Degree* $^{*}$} & 0.0513 & 0.0636 & 0.0294 & 0.0709 \\
\hline & [0.2205] & {$[0.2441]$} & [0.1689] & [0.2567] \\
\hline \multirow[t]{2}{*}{ (log) Cumulative Lifetime Earnings, 1963-1988 } & 13.6600 & 13.6663 & 13.8285 & 13.6316 \\
\hline & [0.8840] & [0.7972] & [0.5155] & [0.8413] \\
\hline \multirow[t]{2}{*}{ (log) Lifetime Average Daily Wage, 1963-1988 } & 4.8011 & 4.8218 & 4.8716 & 4.8112 \\
\hline & {$[0.2822]$} & [0.2740] & [0.2246] & [0.2823] \\
\hline \multirow{2}{*}{ (log) Cumulative Days of Employment, 1963-1988 } & 8.8589 & 8.8444 & 8.9569 & 8.8204 \\
\hline & [0.7323] & [0.6454] & [0.3889] & [0.6856] \\
\hline \multirow[t]{2}{*}{ (log) Real Daily Wage at Age $30^{+}$} & 4.3795 & 4.5840 & 4.6433 & 4.5706 \\
\hline & {$[0.2809]$} & [0.2905] & [0.2489] & [0.2975] \\
\hline \multirow[t]{2}{*}{ (log) Real Daily Wage at Age $40^{+}$} & 4.8695 & 4.9818 & 5.0190 & 4.9735 \\
\hline & [0.2828] & [0.2859] & [0.2363] & [0.2952] \\
\hline \multirow[t]{2}{*}{ (log) Real Daily Wage at Age $50^{+}$} & 5.0389 & 5.1060 & 5.1390 & 5.1011 \\
\hline & [0.3271] & [0.3363] & [0.2764] & [0.3441] \\
\hline Observations & 10,027 & 11,981 & 2,111 & 9,870 \\
\hline
\end{tabular}

NOTES: * indicates an dummy variable. Standard deviations are in brackets. ${ }^{\dagger}$ Since the dataset is not a balanced panel, the number of observations used to compute these summary statistics do not correspond with the last row of the table. 
TABLE 2 -OLS Estimates OF THE RETURNS tO CMS

\begin{tabular}{|c|c|c|c|c|}
\hline & \multicolumn{2}{|c|}{ Full Sample } & \multicolumn{2}{|c|}{ Cohort 1936-1938 } \\
\hline & (1) & $(2)$ & & (4) \\
\hline \multicolumn{5}{|c|}{ Panel A: (log) Lifetime Average Daily Wage } \\
\hline Military Service & $\begin{array}{c}0.0655^{* * *} \\
{[0.0052]}\end{array}$ & $\begin{array}{c}0.0466^{* * *} \\
{[0.0053]}\end{array}$ & $\begin{array}{c}0.0492^{* * *} \\
{[0.0099]}\end{array}$ & $\begin{array}{c}0.0461^{* * *} \\
{[0.0097]}\end{array}$ \\
\hline High School & - & $\begin{array}{c}0.1925^{* * *} \\
{[0.0042]}\end{array}$ & - & $\begin{array}{c}0.1945^{* * *} \\
{[0.0064]}\end{array}$ \\
\hline University & - & $\begin{array}{c}0.3998^{* * * *} \\
{[0.0083]}\end{array}$ & - & $\begin{array}{c}0.4056^{* * * *} \\
{[0.0127]}\end{array}$ \\
\hline \multicolumn{5}{|c|}{ Panel B: (log) Cumulative Days of Employment } \\
\hline Military Service & $\begin{array}{c}0.1171^{* * *} \\
{[0.0098]}\end{array}$ & $\begin{array}{c}0.1269^{* * *} \\
{[0.0107]}\end{array}$ & $\begin{array}{c}0.1388^{* * *} \\
{[0.0196]}\end{array}$ & $\begin{array}{c}0.1175^{* * *} \\
{[0.0208]}\end{array}$ \\
\hline High School & - & $\begin{array}{c}0.2436^{* * * *} \\
{[0.0130]}\end{array}$ & - & $\begin{array}{c}0.2490^{* * *} \\
{[0.0217]}\end{array}$ \\
\hline University & - & $\begin{array}{c}0.1531^{* * *} \\
{[0.0226]}\end{array}$ & - & $\begin{array}{c}0.1686^{* * *} \\
{[0.0343]}\end{array}$ \\
\hline \multicolumn{5}{|c|}{ Panel C: $(\log )$ Cumulative Lifetime Earnings } \\
\hline Military Service & $\begin{array}{c}0.1826^{* * *} \\
{[0.0127]}\end{array}$ & $\begin{array}{c}0.1735^{* * *} \\
{[0.0136]}\end{array}$ & $\begin{array}{c}0.1880^{* * *} \\
{[0.0251]}\end{array}$ & $\begin{array}{c}0.1636^{* * *} \\
{[0.0261]}\end{array}$ \\
\hline High School & - & $\begin{array}{c}0.4357^{* * * *} \\
{[0.0152]}\end{array}$ & - & $\begin{array}{c}0.4436^{* * *} \\
{[0.0235]}\end{array}$ \\
\hline University & - & $\begin{array}{c}0.5529^{* * *} \\
{[0.0279]}\end{array}$ & - & $\begin{array}{c}0.5742^{* * * *} \\
{[0.0423]}\end{array}$ \\
\hline Controls & No & Yes & No & Yes \\
\hline Observations & & & & \\
\hline
\end{tabular}

NOTES: Wage and earnings are in 1995 DM. Bracketed numbers are robust standard errors clustered at the day of birth. See text for the list of other control variables. ${ }^{*} p<0.10,{ }^{* *} p<0.05,{ }^{* * *} p<0.01$. 


\begin{tabular}{|c|c|c|c|c|c|c|}
\hline & \multicolumn{2}{|c|}{$\begin{array}{c}(\log ) \text { Lifetime } \\
\text { Average Daily Wage }\end{array}$} & \multicolumn{2}{|c|}{$\begin{array}{l}\text { (log) Cumulative Days } \\
\text { of Employment }\end{array}$} & \multicolumn{2}{|c|}{$\begin{array}{l}\text { (log) Cumulative } \\
\text { Lifetime Earnings }\end{array}$} \\
\hline & (1) & (2) & (3) & (4) & (5) & (6) \\
\hline \multicolumn{7}{|c|}{ Panel A: Global Polynomial- and Spline-Based 2SLS Estimates } \\
\hline \multirow[t]{2}{*}{ Military Service } & 0.0849 & 0.0335 & -0.1607 & -0.0530 & -0.0759 & -0.0195 \\
\hline & [0.1271] & [0.0964] & [0.3188] & [0.2456] & [0.3900] & [0.2986] \\
\hline F-statistic & 34.44 & 271.27 & 34.44 & 271.27 & 34.44 & 271.27 \\
\hline Partial $R^{2}$ & 0.0027 & 0.0045 & 0.0027 & 0.0045 & 0.0027 & 0.0045 \\
\hline Controls & \multicolumn{2}{|c|}{ Yes } & \multicolumn{2}{|c|}{ Yes } & \multicolumn{2}{|c|}{ Yes } \\
\hline Observations & \multicolumn{2}{|c|}{22,008} & \multicolumn{2}{|c|}{22,008} & \multicolumn{2}{|c|}{22,008} \\
\hline \multicolumn{7}{|c|}{$\begin{array}{l}\text { Panel B: Local Linear Regressions } \\
\text { (i) Preferred Bandwidth }\end{array}$} \\
\hline Military Service & $\begin{array}{c}0.1021 \\
{[0.2155]}\end{array}$ & $\begin{array}{c}0.0955 \\
{[0.2177]}\end{array}$ & $\begin{array}{l}-0.3590 \\
{[0.5324]}\end{array}$ & $\begin{array}{l}-0.3118 \\
{[0.5471]}\end{array}$ & $\begin{array}{l}-0.2366 \\
{[0.6174]}\end{array}$ & $\begin{array}{l}-0.3066 \\
{[0.7040]}\end{array}$ \\
\hline \multicolumn{7}{|c|}{ (ii) 50 Percent of Preferred Bandwidth } \\
\hline \multirow[t]{2}{*}{ Military Service } & 0.1581 & 0.1361 & -0.5602 & -0.7108 & -0.3125 & -0.9397 \\
\hline & [0.4943] & [0.7165] & [1.4168] & [7.6684] & [1.8303] & [10.7459] \\
\hline \multicolumn{7}{|c|}{ (iii) 150 Percent of Preferred Bandwidth } \\
\hline \multirow[t]{2}{*}{ Military Service } & 0.1251 & 0.1353 & -0.2957 & -0.3311 & -0.1087 & -0.0553 \\
\hline & [0.1651] & [0.1710] & [0.4032] & [0.4507] & [0.4581] & [0.5455] \\
\hline
\end{tabular}

NOTES: In Panel A, odd columns report estimates using polynomials; even columns report spline-based estimates. In Panel B, odd columns report estimates based on the triangular kernel; even columns report estimates based on the rectangular kernel. Wage and earnings are in 1995 DM. Bracketed numbers are robust standard errors clustered at the day of birth for Panel A and bootstrapped using 500 replications for Panel B. The $F$-statistic and partial $R^{2}$ are from the first-stage regressions. See text for the list of control variables. ${ }^{*} p<0.10,{ }^{* *} p<0.05,{ }^{* * *} p<0.01$. 
TABLE 4 -ALternative IV EstimAtes OF THE RETURNS TO CMS

\begin{tabular}{|c|c|c|c|c|c|c|}
\hline & \multicolumn{2}{|c|}{$\begin{array}{c}\text { (log) Lifetime } \\
\text { Average Daily Wage }\end{array}$} & \multicolumn{2}{|c|}{$\begin{array}{l}\text { (log) Cumulative Days } \\
\text { of Employment }\end{array}$} & \multicolumn{2}{|c|}{$\begin{array}{l}\text { (log) Cumulative } \\
\text { Lifetime Earnings }\end{array}$} \\
\hline & (1) & (2) & (3) & (4) & (5) & (6) \\
\hline \multirow[t]{2}{*}{ Military Service } & 0.0912 & 0.0646 & -0.0348 & -0.0537 & 0.0565 & 0.0109 \\
\hline & {$[0.0612]$} & {$[0.0790]$} & [0.1516] & {$[0.2051]$} & [0.1866] & [0.2519] \\
\hline \multirow[t]{2}{*}{ High School } & $0.1902^{* * *}$ & $0.1941^{* * *}$ & $0.2506^{* * *}$ & $0.2534^{* * *}$ & $0.4408^{* * *}$ & $0.4475^{* * *}$ \\
\hline & {$[0.0050]$} & {$[0.0068]$} & [0.0146] & {$[0.0211]$} & {$[0.0173]$} & [0.0247] \\
\hline \multirow[t]{2}{*}{ University } & $0.2109^{* * *}$ & $0.2120^{* * *}$ & $-0.1025^{* * *}$ & $-0.0888^{* * *}$ & $0.1085^{* * *}$ & $0.1232^{* * *}$ \\
\hline & [0.0089] & {$[0.0126]$} & {$[0.0221]$} & [0.0311] & {$[0.0279]$} & [0.0393] \\
\hline$F$-statistic & 357.88 & 67.28 & 357.88 & 67.28 & 357.88 & 67.28 \\
\hline Partial $R^{2}$ & 0.0103 & 0.0234 & 0.0103 & 0.0234 & 0.0103 & 0.0234 \\
\hline Controls & \multicolumn{2}{|c|}{ Yes } & \multicolumn{2}{|c|}{ Yes } & \multicolumn{2}{|c|}{ Yes } \\
\hline Observations & 22,008 & 9,322 & 22,008 & 9,322 & 22,008 & 9,322 \\
\hline
\end{tabular}

NOTES: Odd columns use the full sample; even columns use Birth Cohort 1936-1938. Wage and earnings are in 1995 DM. Bracketed numbers are robust standard errors clustered at the day of birth. See text for the list of other control variables. The $F$-statistic and partial $R^{2}$ are from the first-stage regressions. ${ }^{*} p<0.10,{ }^{* *} p<0.05,{ }^{* * *} p<0.01$. 


\section{A.2 Figures}

Figure 1 - Probability to be Drafted for Military Service

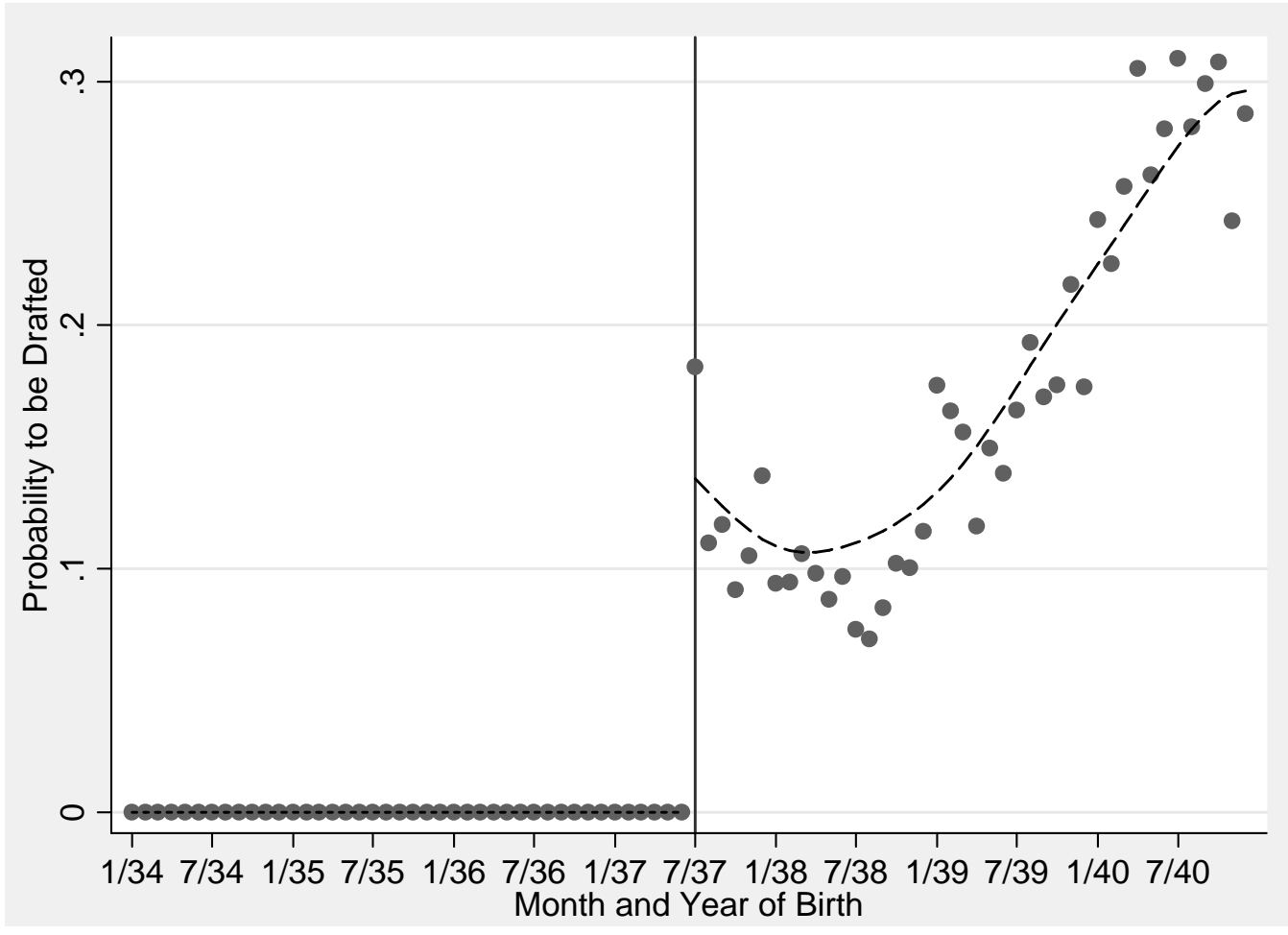

NotE: Dashed lines are Lowess curves over White Cohort and non-White Cohort observations. 
Figure 2 - Age-Earnings Profiles by Birth CoHort And Military Service

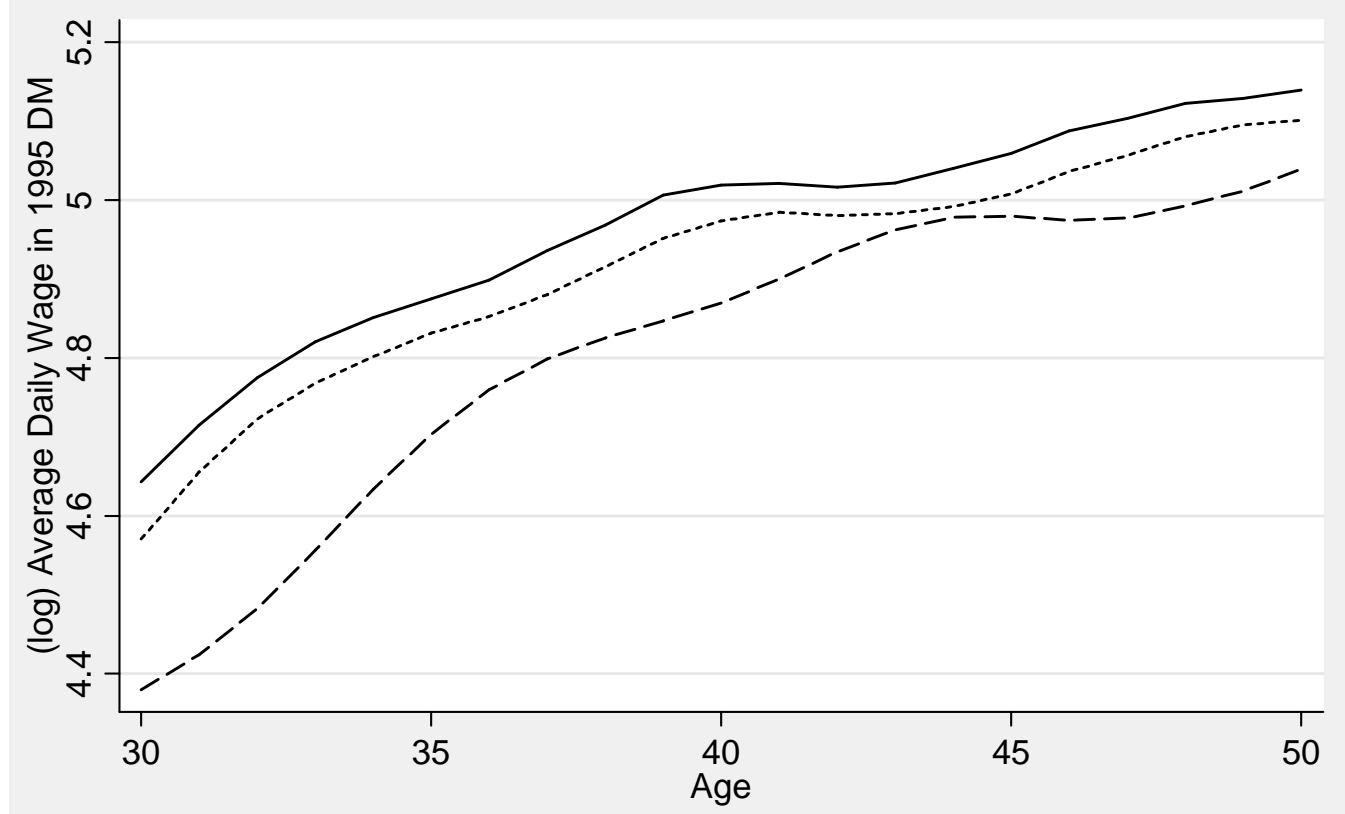
Non-White Cohort, Not Drafted

(a) Full Sample

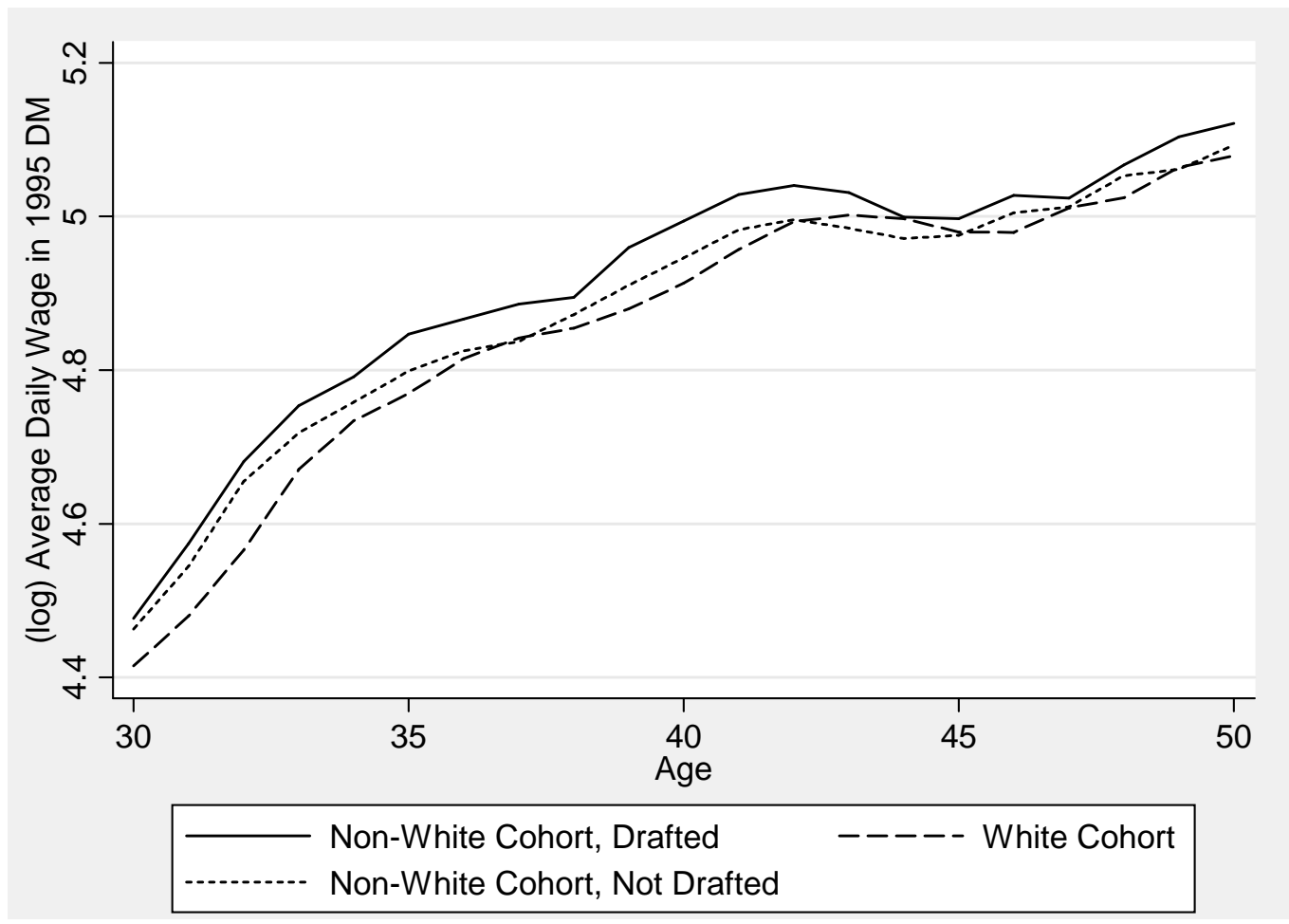

(b) Birth Cohort 1937 
Figure 3 - Earnings and Employment Profiles by Birth Cohort and Military Service

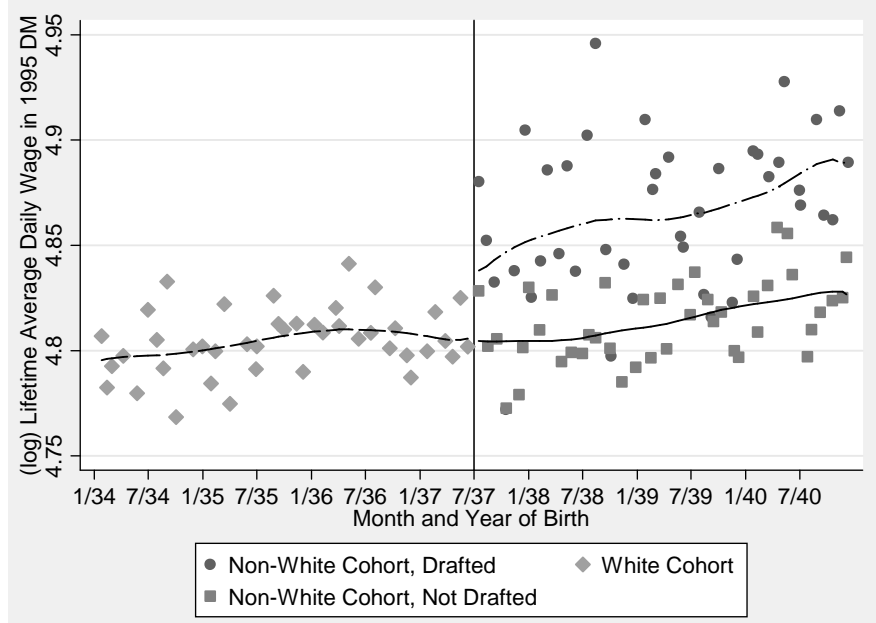

(a) Lifetime Average Daily Wage

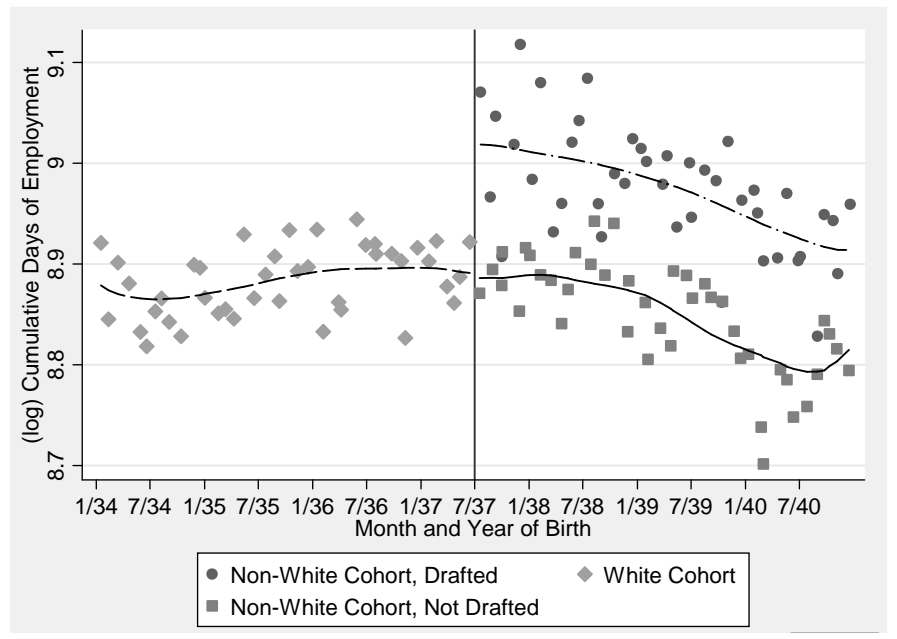

(b) Cumulative Days of Employment

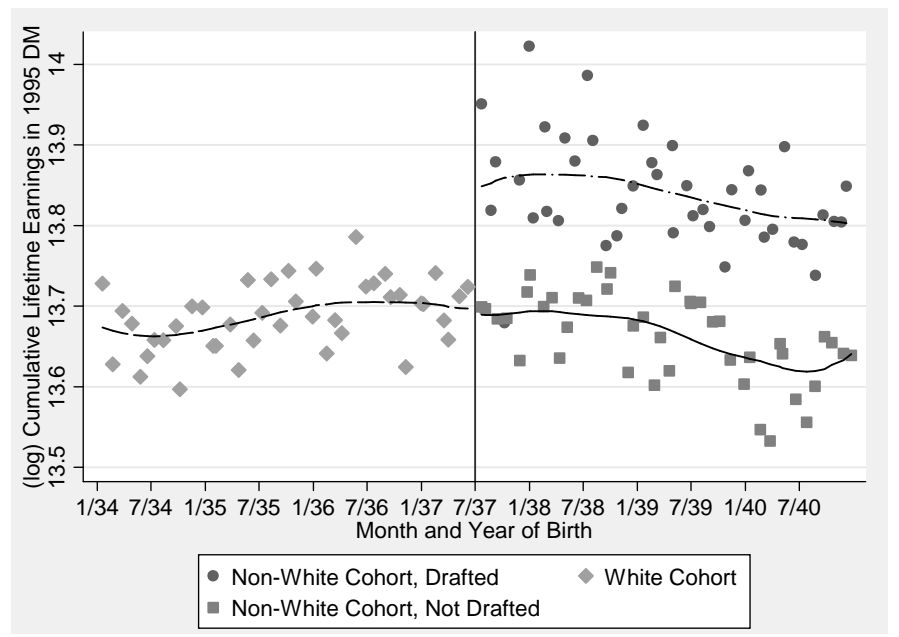

(c) Cumulative Lifetime Earnings

NOTE: Lowess curves are plotted over observations from each sub-group. 
Figure 4 -OlS Estimates of the Returns to CMS on (LOG) Real Daily Gross Wage

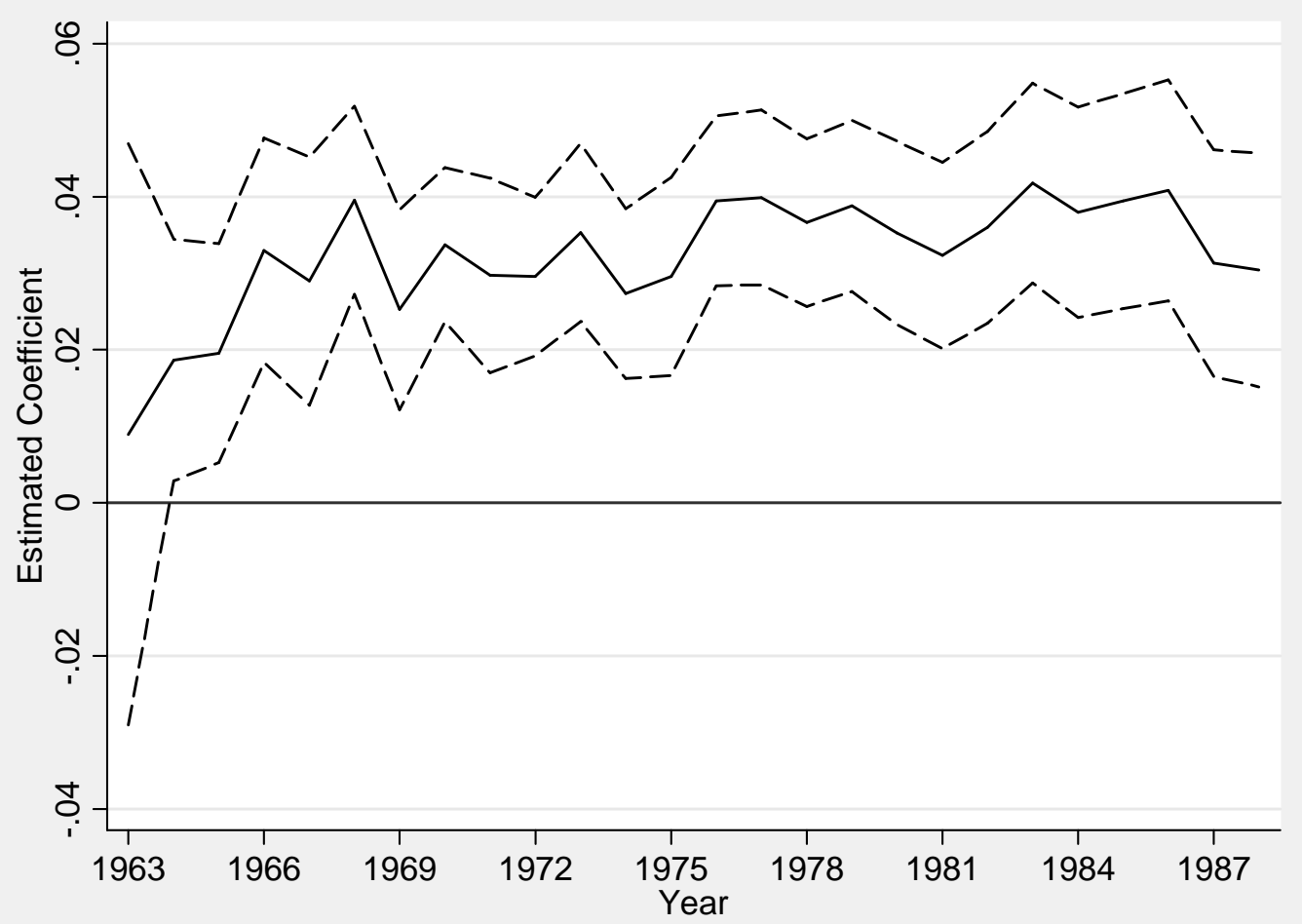

(a) Full Sample

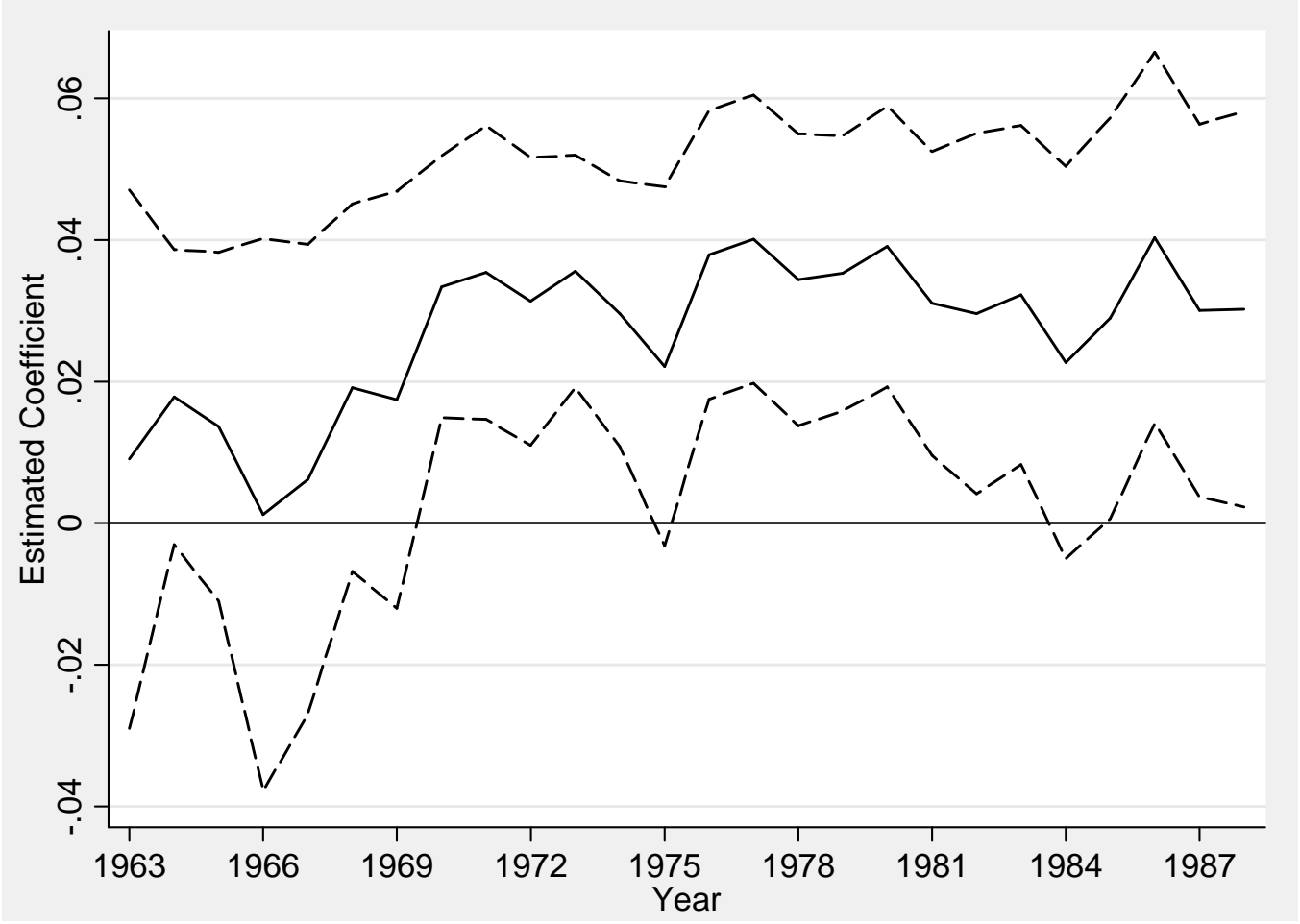

(b) Cohort 1936-1938

Note: Dashed lines encompass the 95-percent confidence interval. 
Figure 5 - Difference in the Outcome Variables at the Cutoff Point

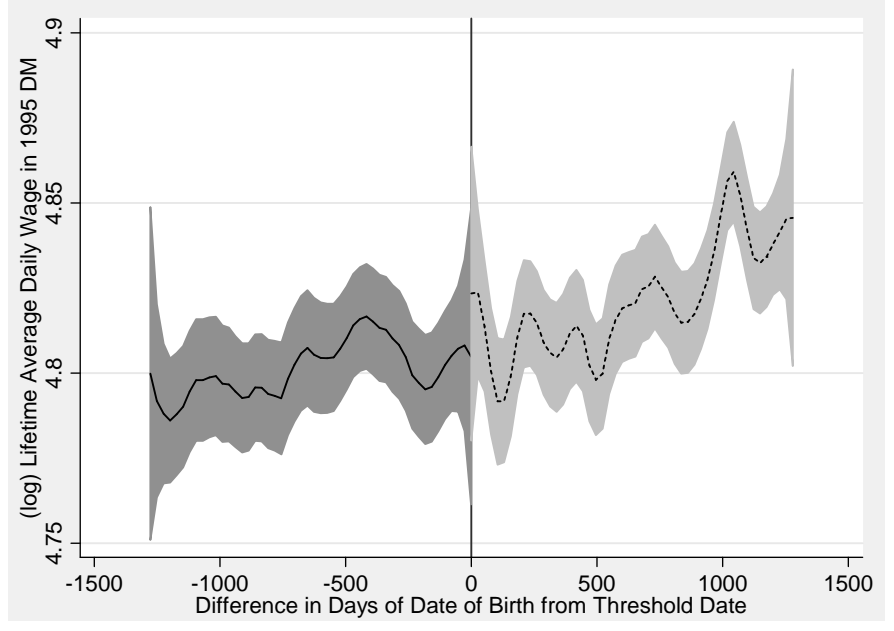

(a) Lifetime Average Daily Wage

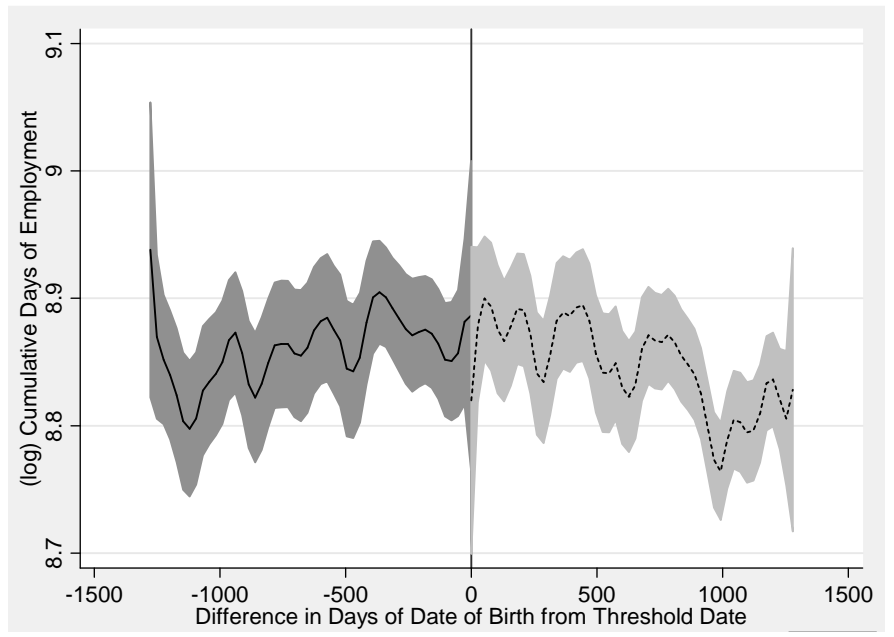

(b) Cumulative Days of Employment

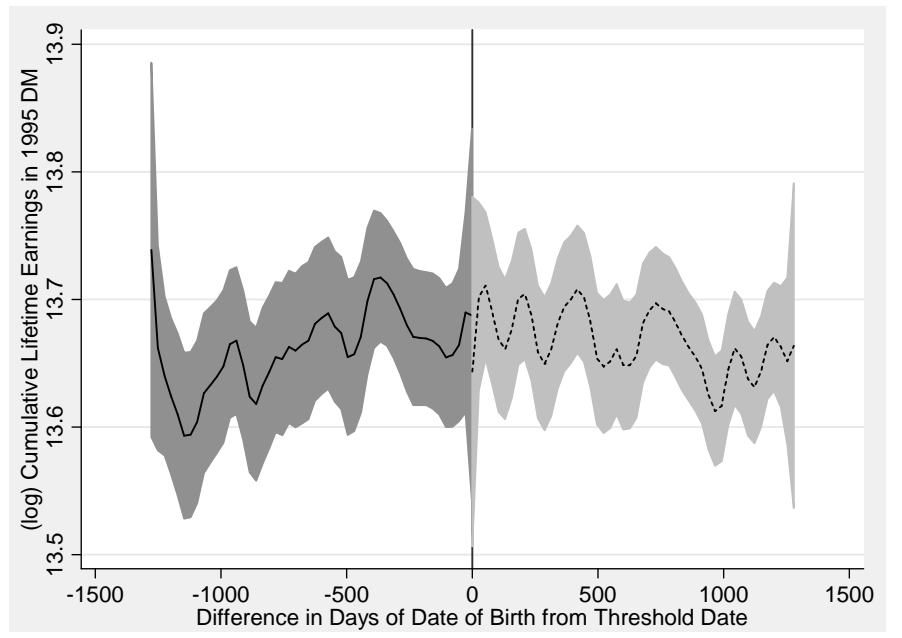

(c) Cumulative Lifetime Earnings

NOTE: Local linear fits are surrounded by shaded areas that represent the 95-percent confidence intervals. 
Figure 6 - Continuity of Covariates at the Cutoff Point

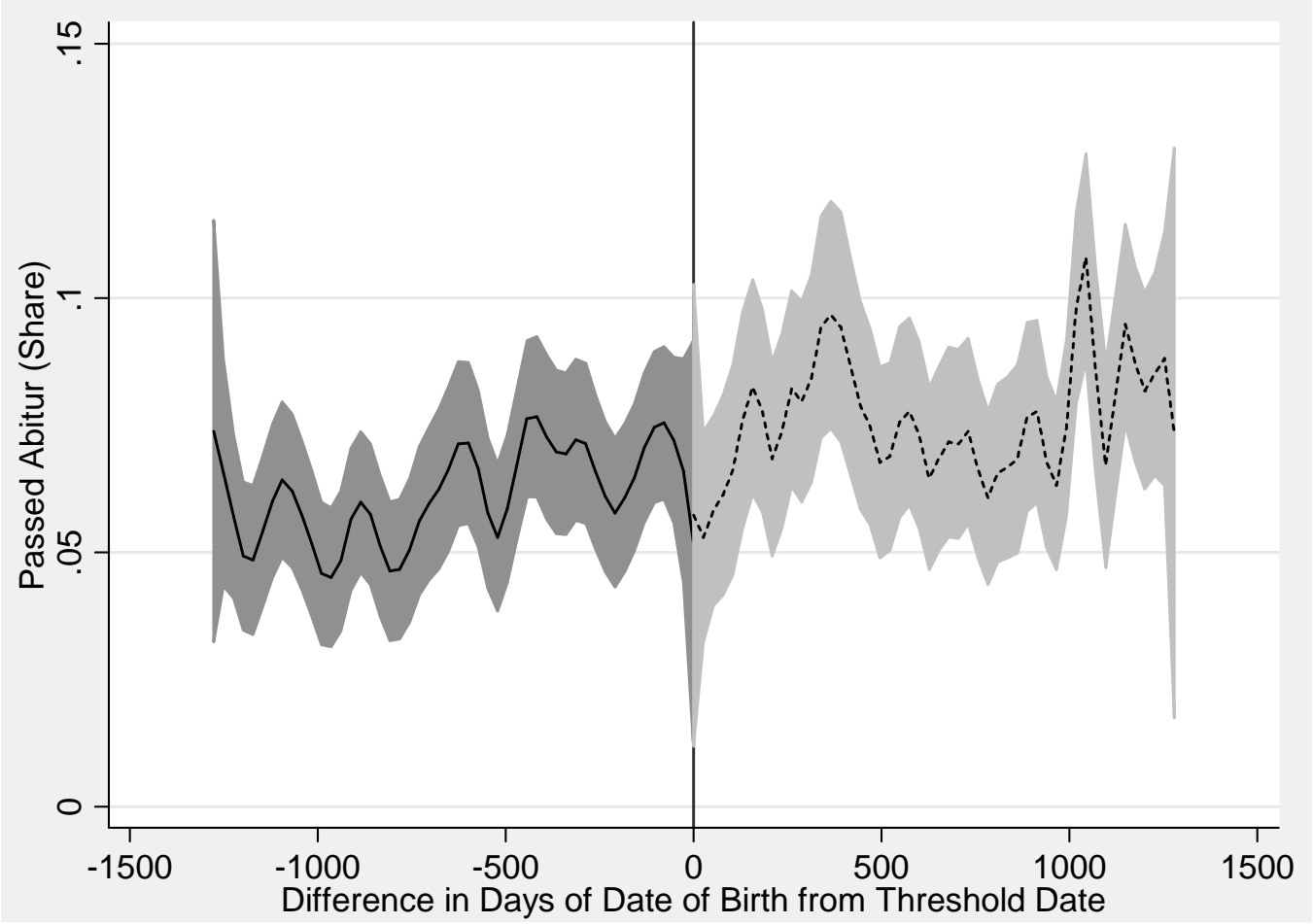

(a) Share of Men who Passed the Abitur

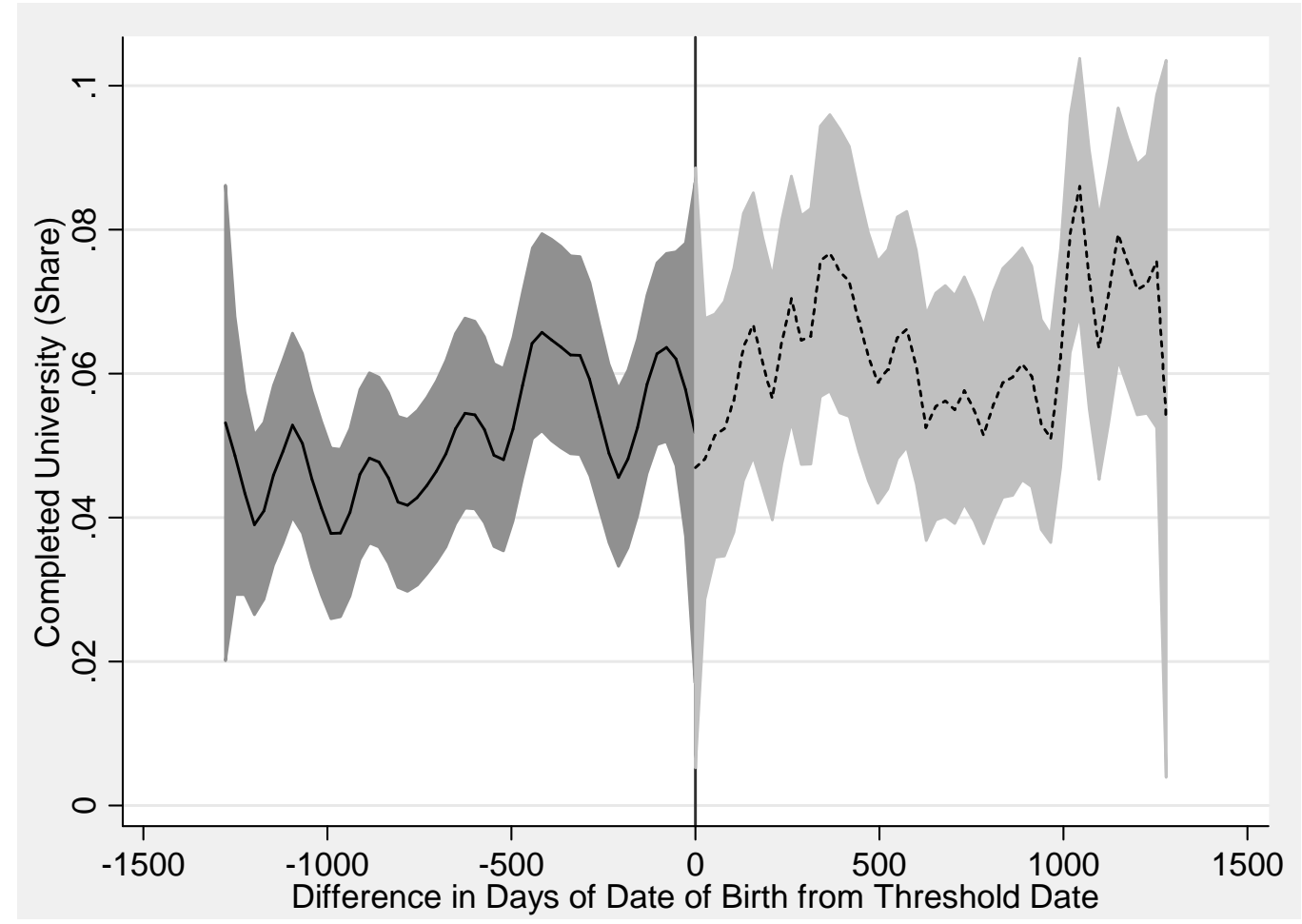

(b) Share of Men who Completed University

NOTE: Local linear fits are surrounded by shaded areas that represent the 95-percent confidence intervals. 
Figure 7 - IV Estimates of the Returns to CMS on (LOG) Real Daily Gross WaGe

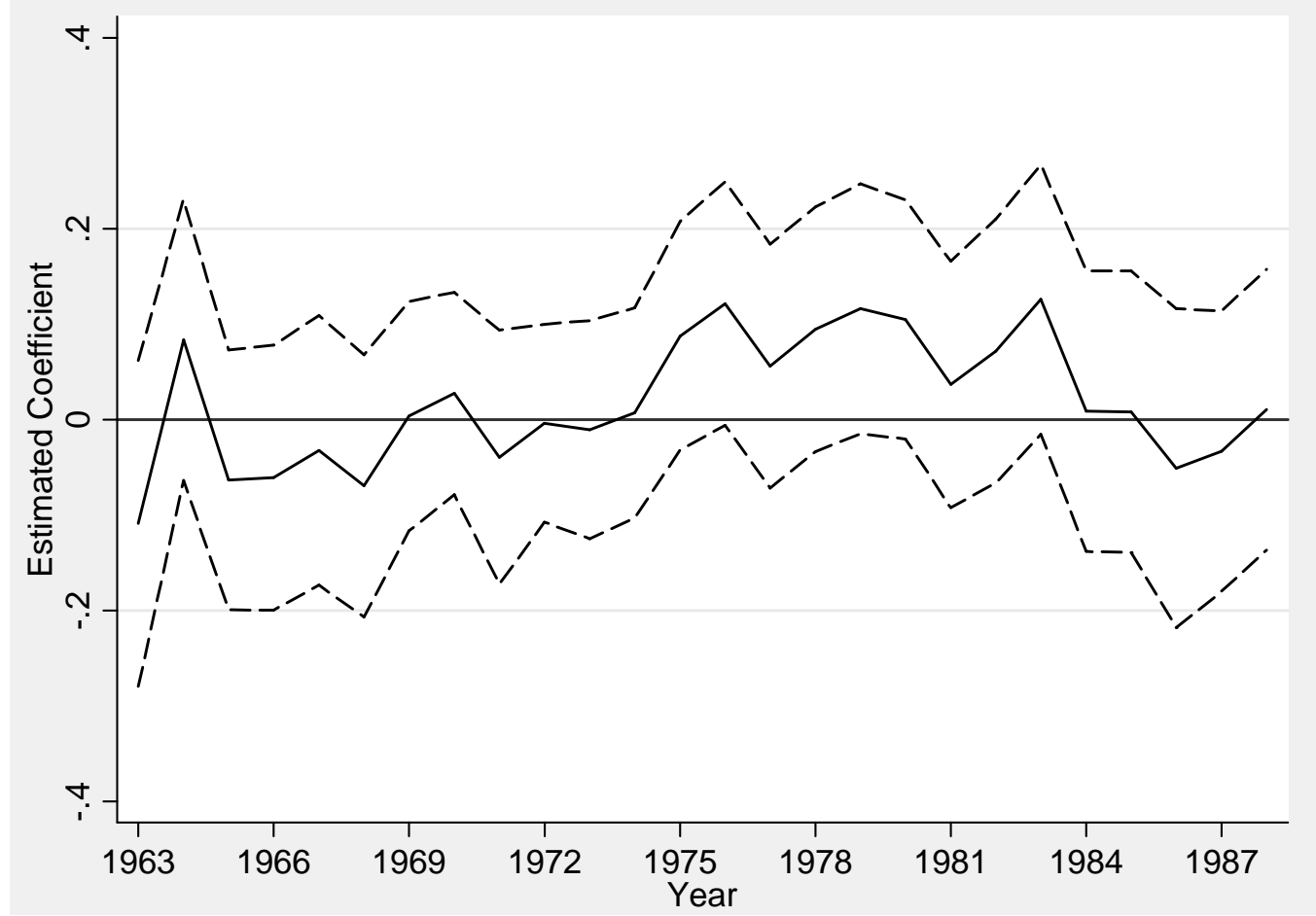

(a) Full Sample

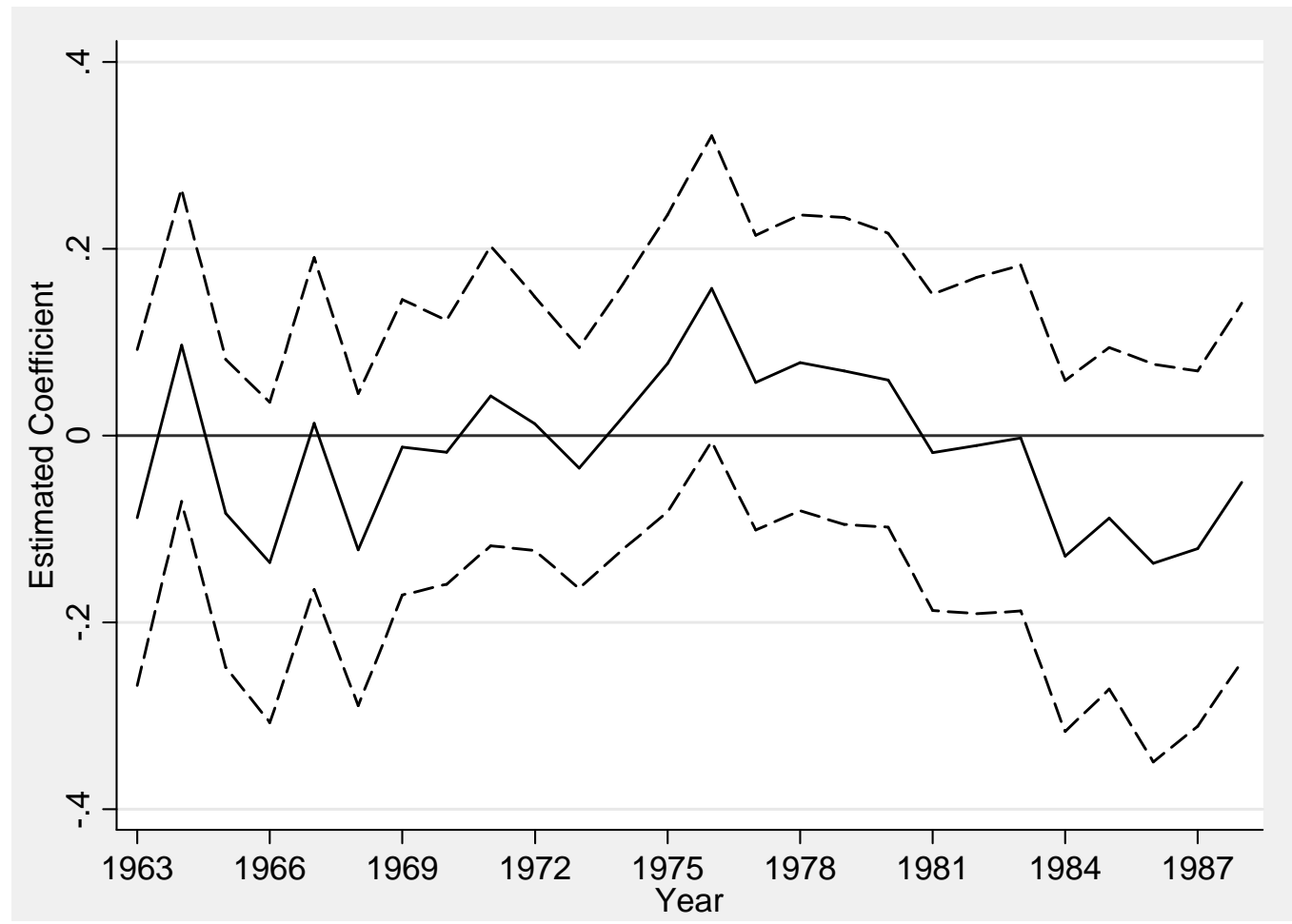

(b) Cohort 1936-1938

NOTES: Dashed lines encompass the 95-percent confidence interval. Instruments are average conscription rate by month of birth. 